\title{
Effect of fluoride toxicity on cardiovascular systems: role of oxidative stress
}

\author{
Ercan Varol $\cdot$ Simge Varol
}

Received: 10 April 2012/Accepted: 25 April 2012/Published online: 10 May 2012

(C) Springer-Verlag 2012

We have read the article published by Ma et al. (2012) with a great interest. They investigated the effect of chronic exposure to arsenic and fluoride alone or combined on inflammatory response in rabbit aorta. They found that fluoride and arsenic alone or combined increased the expression of VCAM-1, P-sel, MCP-1, IL-8, and IL-6 at the RNA and protein levels. We want to share our research findings relating to this study.

Although various effects of chronic fluorosis on different organ systems have been examined, there are really a few studies about the effects of chronic fluorosis on cardiovascular systems. This study is very important from this aspect. In our two previous studies, we examined the effect of chronic fluoride exposure on cardiovascular system in clinical setting as a difference from this experimental study. In our first study, we have found that elastic properties of ascending aorta are impaired in patients with endemic chronic fluorosis (Varol et al. 2010a, b). In this study, we directly examined the aorta by echocardiography and we have showed that chronic fluoride toxicity can cause aortic stiffness in patients with endemic fluorosis. In our second study, we have shown that chronic fluorosis patients had left ventricular diastolic and global dysfunctions (Varol et al. 2010a, b). Oxidative stress is a wellknown mode of action of fluoride exposure that has been observed in vitro in several types of cells and also in vivo in animals and in people living in areas of endemic fluorosis (Barbier et al. 2010). The mechanism of fluoride toxicity on cardiovascular system is complex. We think that in addition to inflammatory mechanism, oxidative stress contributes to atherosclerosis, vascular stiffness, and myocardial cell damage. Fluoride toxicity can cause atherosclerosis at molecular level and can also cause aortic stiffness and disturbed ventricular distensibility at clinical level. Further studies are needed to clarify the effect of fluoride toxicity on cardiovascular system.

\section{References}

Barbier O, Arreola-Mendoza L, Del Razo LM (2010) Molecular mechanisms of fluoride toxicity. Chem Biol Interact 188(2): 319-333

Ma Y, Niu R, Sun Z, Wang J, Luo G, Zhang J, Wang J (2012) Inflammatory responses induced by fluoride and arsenic at toxic concentration in rabbit aorta. Arch Toxicol (Epub ahead of print)

Varol E, Akcay S, Ersoy IH, Ozaydin M, Koroglu BK, Varol S (2010a) Aortic elasticity is impaired in patients with endemic fluorosis. Biol Trace Elem Res 133(2):121-127

Varol E, Akcay S, Ersoy IH, Koroglu BK, Varol S (2010b) Impact of chronic fluorosis on left ventricular diastolic and global functions. Sci Total Environ 408(11):2295-2298
E. Varol ( $\square)$

Department of Cardiology, Faculty of Medicine,

Suleyman Demirel University, Isparta, Turkey

e-mail: drercanvarol@yahoo.com

S. Varol

Department of Geology, Faculty of Engineering,

Suleyman Demirel University, Isparta, Turkey 